\title{
CORRECTION
}

\section{Correction: Recovery from bradycardia and desaturation events at 32 weeks corrected age and NICU length of stay: an indicator of physiologic resilience?}

V. Peter Nagraj, Robert A. Sinkin, Douglas E. Lake, J. Randall Moorman and Karen D. Fairchild

Pediatric Research (2020) 88:821; https://doi.org/10.1038/s41390-020-0822-9

Correction to: Pediatric Research (2019) 86, 622-627, https://doi. org/10.1038/s41390-019-0488-3, published online 04 July 2019

In the original version of this article, two funding sources were inadvertently omitted by the publisher. The following text has now been added under the heading 'Acknowledgements': "This study was funded by National Institutes of Health HD072071 and HD064488". This has been corrected in both the PDF and HTML versions of the article. 